\title{
Fire and vegetation change during the Early Pleistocene in southeastern Australia
}

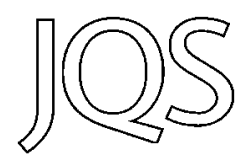

\author{
J. M. KALE SNIDERMAN ${ }^{1,2 *}$ and SIMON G. HABERLE ${ }^{3}$ \\ ${ }^{1}$ School of Geography and Environmental Science, Monash University, Clayton, Victoria, Australia \\ ${ }^{2}$ School of Plant Science, University of Tasmania, Hobart, Tasmania, Australia \\ ${ }^{3}$ Department of Archaeology and Natural History, School of Culture, History and Language, College of Asia and the Pacific, \\ Australian National University, Canberra, ACT, Australia \\ Received 11 April 2011; Revised 8 August 2011; Accepted 5 September 2011
}

\begin{abstract}
Early Pleistocene vegetation in upland southeastern Australia included diverse rainforests and sclerophyll forests, which alternated on precessional timescales. The nature and timing of transitions between these biomes, and the role of fire in maintaining or driving transitions between them, are uncertain. Here we present a high-resolution pollen record from Stony Creek Basin, a small Early Pleistocene palaeolake in southeastern Australia. The pollen record documents a pattern of vegetation change, over ca. 10 ka at ca. 1590-1600 ka, between sclerophyll forests, dominated by Eucalyptus, Callitris (Cupressaceae) or Casuarinaceae, and rainforests dominated by either angiosperms or conifers of the family Podocarpaceae. Transitions between these biomes typically occurred within ca. 1-2 ka. The associated charcoal record suggests that greatest biomass combustion occurred when local vegetation was dominated by Eucalyptus, and the least biomass combustion occurred when local vegetation was dominated by Podocarpaceae. However, local fires burnt in both sclerophyll and angiosperm-dominated rainforest vegetation, at least once every several centuries. Fire was very rare (less than about one fire per millennium) only when the local vegetation was rainforest dominated by Podocarpaceae. This suggests that fire was an irregular presence in both sclerophyll- and angiosperm-dominated rainforest biomes during the late Neogene, though was largely absent in Podocarpaceae-dominated rainforests. Copyright (C) 2011 John Wiley \& Sons, Ltd.
\end{abstract}

KEYWORDS: pollen; sclerophyll; Early Pleistocene; fire; rainforest.

\section{Introduction}

During the Early Pleistocene (2.59-0.78 Ma) the vegetation of upland southeastern Australia appears to have alternated between more closed communities (temperate rainforests) and sclerophyll-dominated communities with a rhythm dominated by the 23 ka period of orbital precession (Sniderman et al., 2007). Sniderman (2011) illustrated patterns of recurrent rainforest-sclerophyll alternation in the ca. $280 \mathrm{ka}$ long pollen record of palaeolake Stony Creek Basin (SCB; Fig. 1), which at finer scale involved changes in dominance between coniferand angiosperm-dominated rainforest, and between the dominant sclerophyll forest taxa Eucalyptus (Myrtaceae), Casuarinaceae and Callitris (Cupressaceae), indicating a dynamic history of vegetation change in both rainforest and non-rainforest components of the regional vegetation. In that record, many transitions between vegetation phases appeared instantaneous, occurring across single sample intervals. The $\sim 20 \mathrm{~cm}$ sampling interval of the $\sim 40 \mathrm{~m}$ long record corresponds to ca. 0.5-2 ka between samples, suggesting that some Early Pleistocene vegetation changes occurred rapidly. Analysis of microscopic (pollen-slide) charcoal by Sniderman (2011) indicated that charcoal abundance was correlated with major changes in pollen values, primarily at pollen-zone boundaries. This implies that fire played a role in, or accompanied, vegetation changes during the Early Pleistocene. In order to gain a more detailed understanding of the pattern and timing of the vegetation successions evident at $\mathrm{SCB}$, and to explore the possible role of fire in maintaining different vegetation types or driving transitions between them, here we present a high-resolution pollen and charcoal record documenting the onset and development of one rainforest-dominated episode in the SCB record, and its subsequent replacement by sclerophyll forest vegetation.

The presence within sedimentary deposits of macroscopic charcoal (hereafter macrocharcoal), defined as charcoal particles with longest dimension $>125 \mu \mathrm{m}$, is thought to

*Correspondence: J. M. K. Sniderman, as above.

E-mail: kale.sniderman@monash.edu largely reflect catchment-scale deposition of the products of biomass burning (Clark, 1988; Clark and Royall, 1995; Millspaugh and Whitlock, 1995; Higuera et al., 2007; Conedera et al., 2009), in contrast to microcharcoal (with longest dimension typically $10-100 \mu \mathrm{m}$ ), which is susceptible to transport over great distances and therefore integrates histories of vegetation combustion over regional to subcontinental scales. In this study we quantified macrocharcoal concentrations in order to examine the role of fire in catchmentscale vegetation change. We analysed the $322-470 \mathrm{~cm}$ SCB core interval (representing the uppermost portion of zone S-5, all of zone S-4, and the lowermost portion of zone S-3 of Sniderman (2011), corresponding to the interval between 1588 and $1600 \mathrm{ka}$ in the age model of Sniderman et al., 2007) (Fig. 2). This interval was selected for three reasons: (i) its composition, pollen successions, and stratigraphic thickness are similar to the succession of five other rainforest-dominated zones S-10, S-8, S-6, S-4 and S-1 (Fig. 2); (ii) it offered the possibility of highresolution correlation with parallel studies of plant macrofossils (Jordan et al., 2007) and fossil beetles (Sniderman et al., 2009); and (iii) the selected interval lies well below a zone of partial sediment oxidation in the upper $\sim 2 \mathrm{~m}$ of the sediment record.

\section{Study area}

Stony Creek Basin $\left(144.13^{\circ} \mathrm{E}, 37.35^{\circ} \mathrm{S}, 550 \mathrm{~m}\right.$ above sea level) is a small ( 10 ha), infilled palaeolake in southeastern Australia (Sniderman et al., 2007). SCB lies in Victoria's western uplands (Joyce, 1992), a band of dissected ranges and plateaux forming part of the continental divide, ranging from 300 to $1000 \mathrm{~m}$ above sea level. The region experiences cool, wet winters and warm, dry summers, governed by the seasonal migration of the Southern Hemisphere subtropical anticyclone (Sniderman et al., 2009). Natural vegetation consists primarily of open forests dominated by Eucalyptus with a grassy or heathy understorey. Limited areas with annual rainfall $>1000 \mathrm{~mm}$ support more productive, tall wet eucalypt forests, but rainforest is absent from the western uplands. 


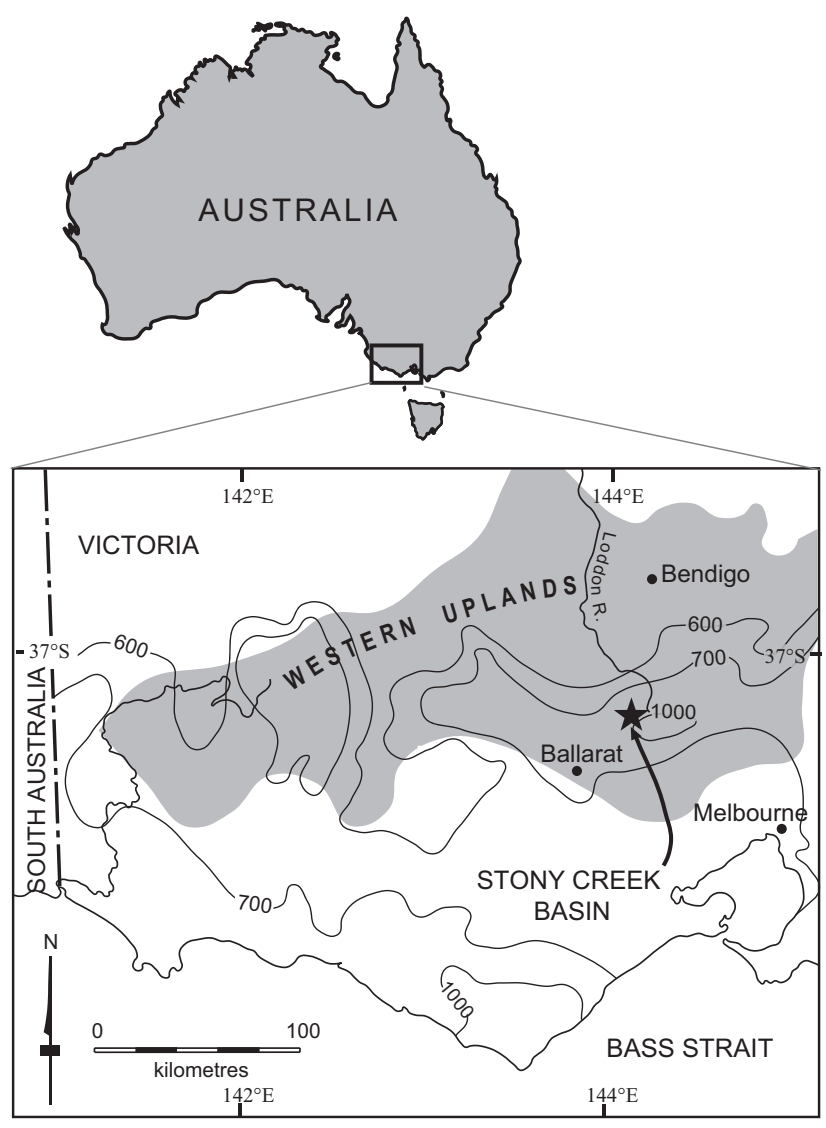

Victoria's Western Uplands

-700- Annual rainfall $(\mathrm{mm})$

Figure 1. Locality of palaeolake SCB within Victoria's western uplands (after Sniderman et al., 2009).

\section{Methods}

\section{Sediment, charcoal and pollen analyses}

For pollen analysis, 44 samples of $1 \mathrm{~cm}^{3}$ were taken at $\sim 3 \mathrm{~cm}$ intervals between 322 and $470 \mathrm{~cm}$ core depth. For moisture content, contiguous, gravimetric samples of $\sim 2 \mathrm{~cm}^{3}$ were taken except where interrupted by core gaps, yielding 139 samples. For charcoal analysis, contiguous, $1 \mathrm{~cm}^{3}$ samples were taken, except where interrupted by core gaps, and within an interval between 440 and $458 \mathrm{~cm}$, where samples were taken every other centimetre, yielding 132 samples. For organic content, approximately every other sample was processed by the loss on ignition (LOI) technique (Dean, 1974).

Preparation of samples for pollen analysis closely followed methods described by Sniderman (2011), except that finesieving (through $7 \mu \mathrm{m}$ mesh) was avoided because of suspicion that small pollen types may have been lost this way in earlier analyses. Samples were disaggregated in 10\% sodium pyrophosphate, immersed in $10 \% \mathrm{KOH}$ at $80^{\circ} \mathrm{C}$, acetolysed, subjected to heavy liquid separation using sodium polytungstate at a specific gravity of 2.0, dehydrated in ethanol, and finally mounted in glycerol on glass slides. Some residues were treated with $48 \%$ HF to eliminate fine silica and diatoms. Pollen counting and plotting procedures were identical to those described by Sniderman (2011), with the exception that aquatic pollen types were calculated relative to a sum that included these types. The average dryland sum was 583, with a minimum of 475. In psimpoll (Bennett, 2005), the pollen diagram was divided into the maximum number of statistically

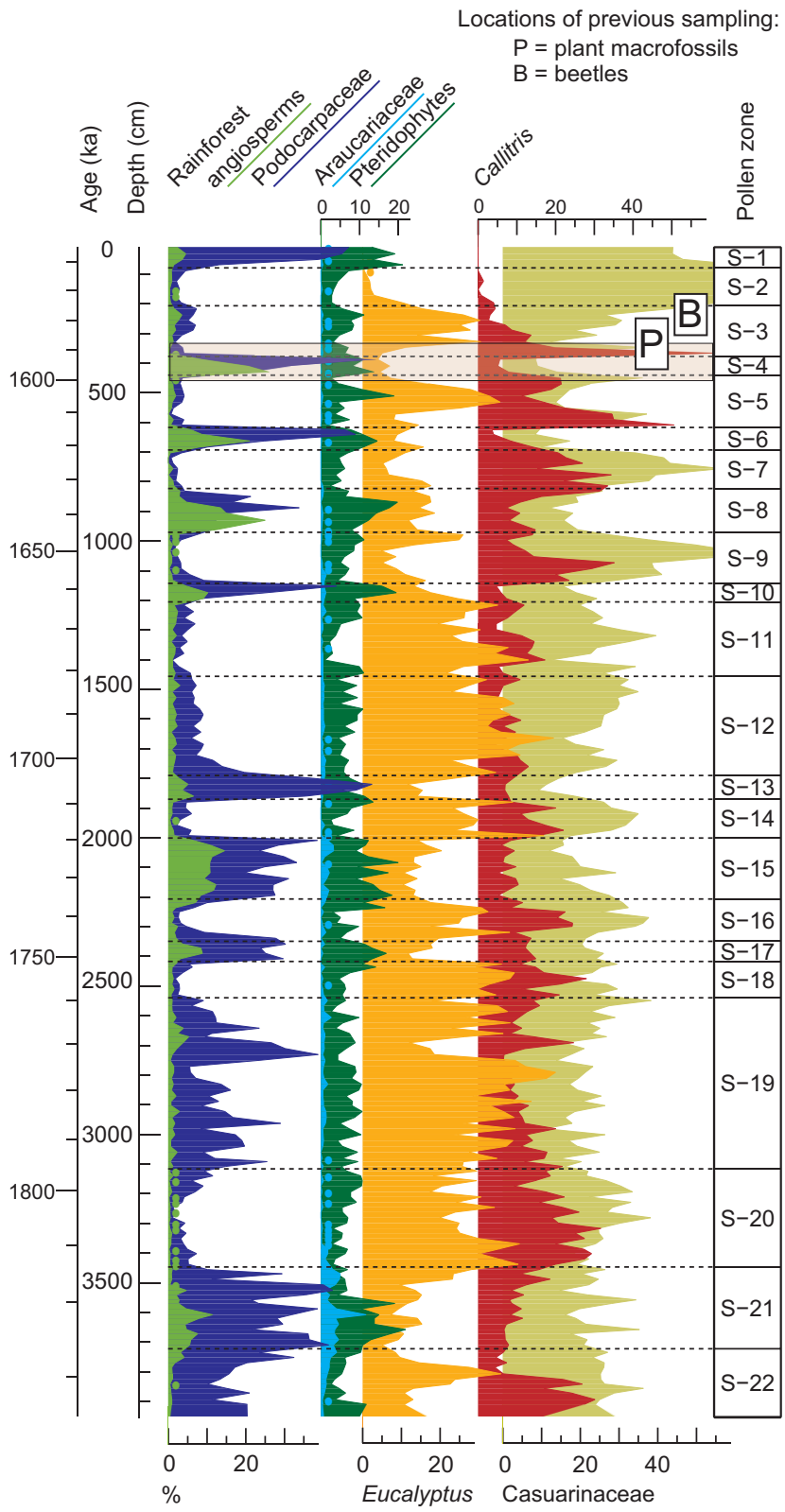

Figure 2. SCB summary pollen diagram, showing location of present study (pale shaded rectangle spanning $322-470 \mathrm{~cm}$ ). Locations of previous sediment sampling for fossil beetles (B; Sniderman et al., 2009) and plant macrofossils (P; Jordan et al., 2007) also shown. This figure is available in colour online at wileyonlinelibrary.com.

significant zones using optimal splitting by information content (Bennett et al., 1992), based on square root-transformed dryland taxa that achieved $\geq 1 \%$ in at least one sample. Principal component analysis (PCA) was used to reduce the variability of the data set to two dimensions, using this same group of taxa. For charcoal analyses, samples were disaggregated in $10 \%$ sodium pyrophosphate and soaked in $6 \%$ bleach for $24 \mathrm{~h}$, then gently washed through a $125 \mu \mathrm{m}$ sieve. Charcoal particles caught on the sieve were transferred to a Petri dish and were counted under low-magnification dissecting microscopy. Mean charcoal count per sample was 368 and ranged from 44 to 1350 .

\section{Development of an age model}

In order to evaluate the timing and duration of changes in the record, it was necessary to develop a high-resolution age model 
for the $322-470 \mathrm{~cm}$ interval, mainly because any variation in sediment deposition time will have influenced charcoal concentrations measured within constant $1 \mathrm{~cm}$ stratigraphic layers. The existing age model for the full SCB record was based primarily on variation in the thickness of annual sediment laminations (varves) across the entire $40 \mathrm{~m}$ record (Sniderman et al., 2007). Its resolution was limited to the precessional scale of individual vegetation cycles, and it cannot be used to model changes in deposition time within these cycles. We developed a detailed age model based on the relationship between varve thickness (indicative of deposition time, or its inverse, sediment accumulation rate), and sediment organic matter and moisture content. For example, in the upper $\sim 30 \mathrm{~m}$ of the SCB record, samples from pollen zones S1, S10, S12 and S1 5 with high LOI and moisture content have relatively thin varves (mean varve thicknesses from 87 to $114 \mu \mathrm{m}$ ), corresponding to high sediment deposition time, while samples from pollen zone S11 with low LOI and low moisture content have relatively thick varves (mean varve thicknesses of 236 and $334 \mu \mathrm{m}$ ), corresponding to low sediment deposition time (see Sniderman et al., 2007, Table DR1). Because in this study moisture content was measured at higher resolution than LOI, we used moisture content to develop an age model, justified by the very significant correlation between LOI and moisture content ( $n=63, r=0.928, P<0.0001)$, which presumably is a function of the high water-retaining capacity of sediment organic matter. Varve thickness and moisture content are significantly correlated in the upper $3375 \mathrm{~cm}$ of the SCB core $(n=16$, $r=0.714, P=0.0019)$. Based on these relationships, we modelled sediment accumulation rate between 322 and $470 \mathrm{~cm}$ based on the assumption that changes in sediment moisture and LOI were surrogates for changes in sediment deposition time.

However, we did not model deposition time directly from moisture-varve thickness relationships, because the 322$470 \mathrm{~cm}$ interval includes LOI values lower than those encountered near any of the measured varve thickness samples, and because few varve measurements were made in sediments above $1000 \mathrm{~cm}$ core depth. Instead, we first developed a topdown constraint on the duration of the $322-470 \mathrm{~cm}$ interval, based on the conclusion of Sniderman et al. (2007) that individual vegetation cycles correspond to precession-paced insolation cycles. In order to limit dependence on Sniderman et al.'s (2007) particular correlation of the SCB record with the astronomical timescale, we calculated a mean sediment deposition time of $75.916 \mathrm{a} \mathrm{cm}^{-1}$ for three contiguous SCB vegetation cycles (from the rainforest peak at $399 \mathrm{~cm}$ to that at $1163 \mathrm{~cm}$, an interval of $764 \mathrm{~cm}$ ), which Sniderman et al. (2007) correlated with the interval from insolation cycle i155 (1597 ka), to i161 (1655 ka), a total of $58 \mathrm{ka}$ (Fig. 2; using the codification of Lourens et al., 1996). We then provided a bottom-up constraint on the maximum deviation from this mean deposition time, by assuming that highest sediment moisture values correspond to the highest sediment deposition times documented from SCB varve thicknesses (thinnest varves $=87.2 \mu \mathrm{m}$, equivalent to ca. $115 \mathrm{a} \mathrm{cm}^{-1}$, at $1615 \mathrm{~cm}$ depth). From these two constraints (mean and maximum sediment deposition times of $75.916 \mathrm{a} \mathrm{cm}^{-1}$ and $115 \mathrm{a} \mathrm{cm}^{-1}$, respectively), we transformed the sediment moisture record into a model of changing sediment deposition time, as follows. We smoothed (5-point weighted smooth) and standardized (mean of zero and unit variance) the $322-470 \mathrm{~cm}$ moisture record. We took the difference between the highest sediment deposition time and the mean $\left(115-75.916=39.084 \mathrm{a} \mathrm{cm}^{-1}\right)$, and divided this by the maximum value of the standardized series (1.812, corresponding to the $408 \mathrm{~cm}$ sample with $53.6 \%$ moisture; Fig. 3), to yield a new standard deviation (39.084/

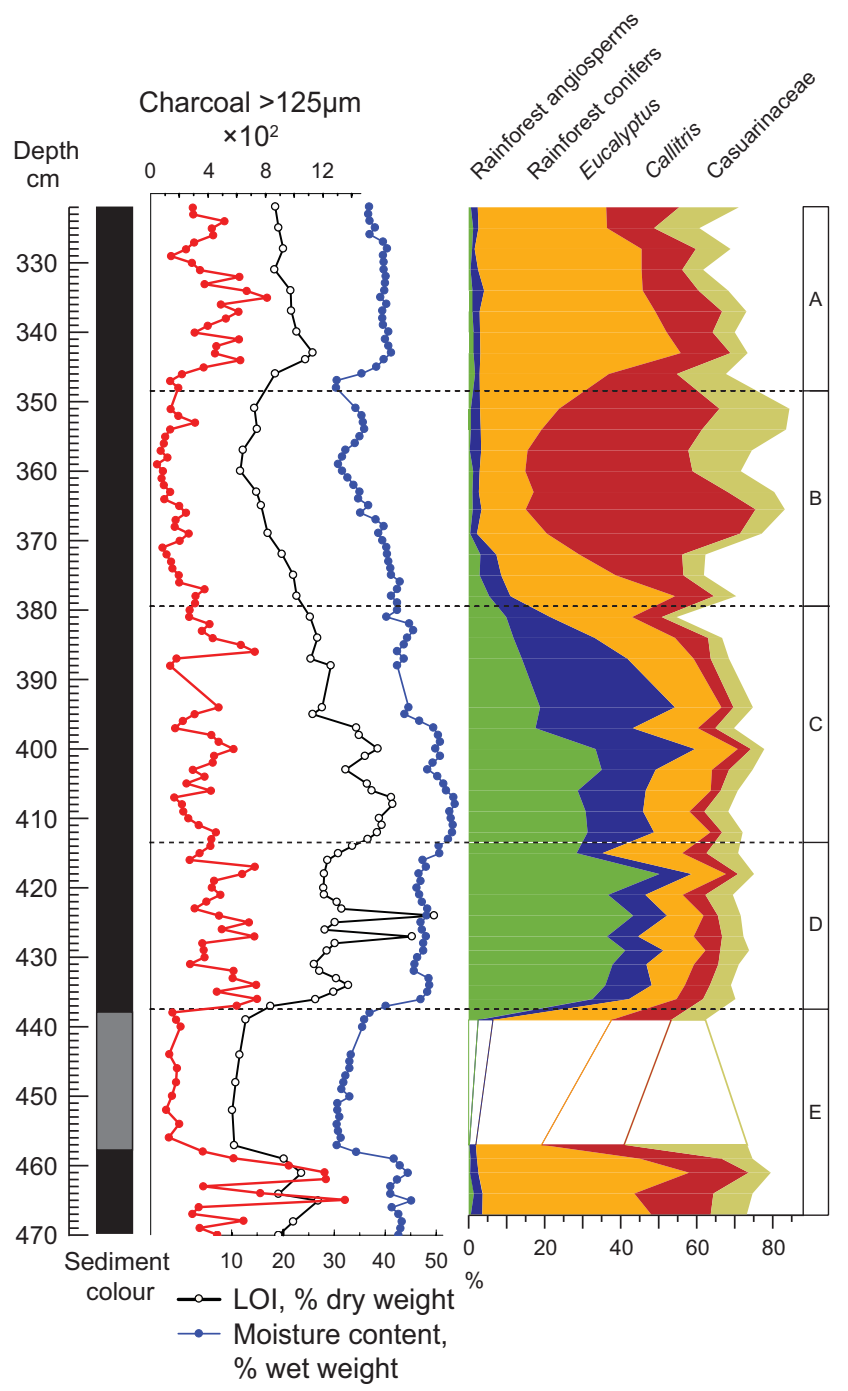

Figure 3. From left to right: sediment colour, raw counts of macroscopic charcoal (>125 $\mu \mathrm{m})$, sediment organic matter (LOI) and moisture content, and summary pollen values. This figure is available in colour online at wileyonlinelibrary.com.

$1.812=21.57)$. Sediment deposition times were then calculated using the following equation:

$$
75.916+x_{i} 21.57
$$

where $x_{i}$ are successive values of the standardized moisture record. These deposition times for each centimetre were then composited into a continuous chronology. Sediment deposition times for uppermost and lowermost samples excluded from the smoothed moisture series were calculated using the same equation, based on unsmoothed values.

The resulting age model is constrained by the inferred maximum duration of the vegetation cycle of which it is a part (average of three consecutive cycles $=19.33 \mathrm{ka}$ ), and by the thinnest varves observed at SCB (Sniderman et al., 2007). Sediment deposition times lower than the mean, corresponding to low-moisture samples, were left unconstrained by varve thickness observations because episodes of most rapid sedimentation appear to coincide with times of low LOI and sediment moisture, when lake levels, and the potential for varve preservation, were probably lowest. Hence the model may fail to capture the lowest deposition times (= highest accumulation rates). Nevertheless, it is likely that the model correctly captures the general pattern of fluctuating sediment deposition times, 
reflected in changing sediment organic matter and moisture content.

\section{Detection of fire history}

Macrocharcoal recovered from lake sediments is thought to consist of two components: a slowly changing 'background', which represents the slow integration of charcoal from regional fire events through the filter of catchment transport processes (Whitlock and Millspaugh, 1996; Marlon et al., 2006); and short-lived charcoal 'peaks', which are thought to represent charcoal produced by fire events occurring within a relatively local scale, plus charcoal contributed through sedimentary and analytical noise (Higuera et al., 2007). In order to reconstruct fire history close to the palaeocatchment at SCB, the macrocharcoal time series was first plotted on the age model described above, interpolated into 76-year bins (the median resolution of the record), then converted into charcoal accumulation rates (particles $\mathrm{cm}^{-2} \mathrm{a}^{-1}$ ). The charcoal accumulation series was then decomposed into background and peak components using CharAnalysis (Higuera et al., 2009; freely available at http://code.google.com/p/charanalysis/). Background charcoal was estimated by smoothing the charcoal time series to a 1500-year window, using a locally weighted least squares regression robust to outliers. Residual charcoal values exceeding background were defined as the peak series. In order to distinguish 'true' local fire events from noise-related variability in the peak series, we assumed that the peak series incorporates normally distributed variation around the back- ground charcoal series (Gavin et al., 2006). In order to separate charcoal peaks from this noise, we used a Gaussian mixture model to estimate the mean and variance of the noise distribution. Fire events were identified as peaks exceeding the 99th percentile of the noise distribution. Finally, peaks were subject to a 'minimum count test' which assesses whether a charcoal count identified as a peak has a $>5 \%$ chance being derived from the same population as counts for the previous five samples, assuming that charcoal counts are Poisson distributed around an unknown real value (Higuera et al., 2010).

\section{Results}

\section{The pollen record}

The pollen diagram (Figs 3 and $4 \mathrm{a}-\mathrm{c}$ ) was divided into five statistically significant zones, described below. For each zone, depth ranges are given along with corresponding durations within the age model. Note that the pollen record extends only down to $467 \mathrm{~cm}$ (corresponding to $9466 \mathrm{a}$ ), while the age model, and sampling for moisture, organic matter and charcoal, extends to $470 \mathrm{~cm}$ (corresponding to $9694 \mathrm{a}$ ).

\section{Zone $E, 437.5-467 \mathrm{~cm}$ (8704-9466 a within the age model)}

Eucalyptus dominates the lowermost four samples (Fig. 4b), its local presence confirmed by pollen clumps, and Callitris achieves relatively high values. Between 438 and $458 \mathrm{~cm}$, a $20 \mathrm{~cm}$ thick band of grey silty clay (Munsell soil colour 10YR 3/

(a)

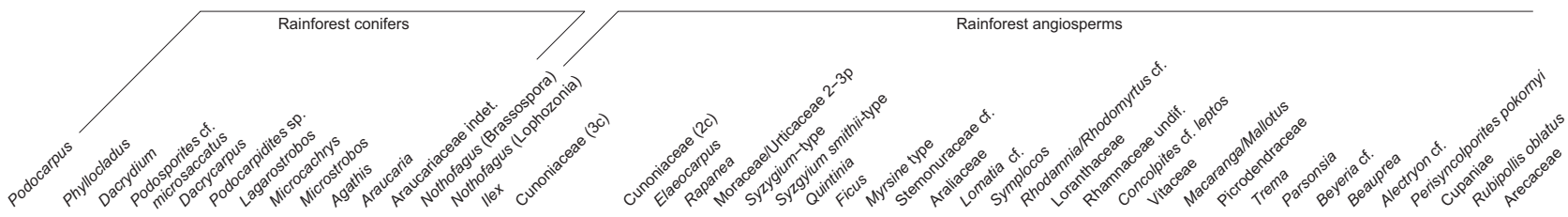

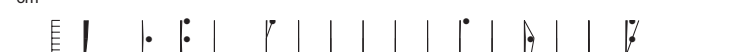

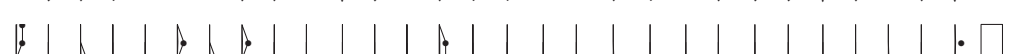

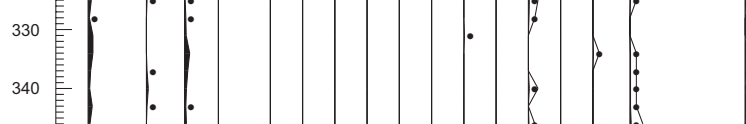

350

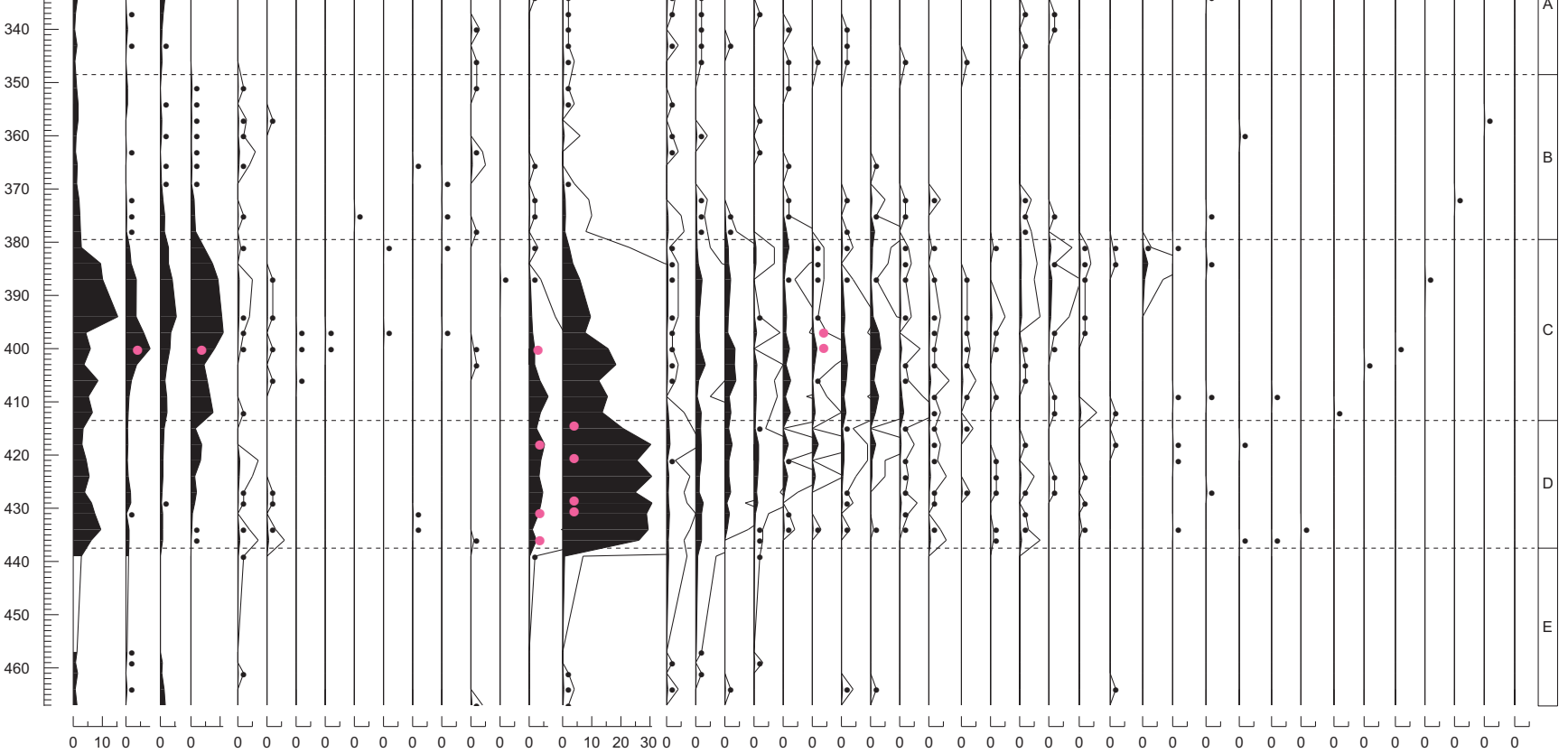

$\% \quad \bullet=$ pollen clump

Figure 4. SCB pollen diagram, 322-467 cm. Pollen percentage values shown as filled lines and with thin, open lines to represent $10 \times$ exaggeration, except between 438 and $458 \mathrm{~cm}$, shown open to indicate presence of 'rip-up clast' sediment. Pale dots indicate presence of clumps of $>2$ grains. (a) Rainforest conifers and angiosperms. (b) Open forest (sclerophyll dominants and mostly woody understorey taxa). (c) Open forest (mostly herbaceous understorey taxa), the dryland sum, pteridophytes and allies, and aquatics. This figure is available in colour online at wileyonlinelibrary.com. 

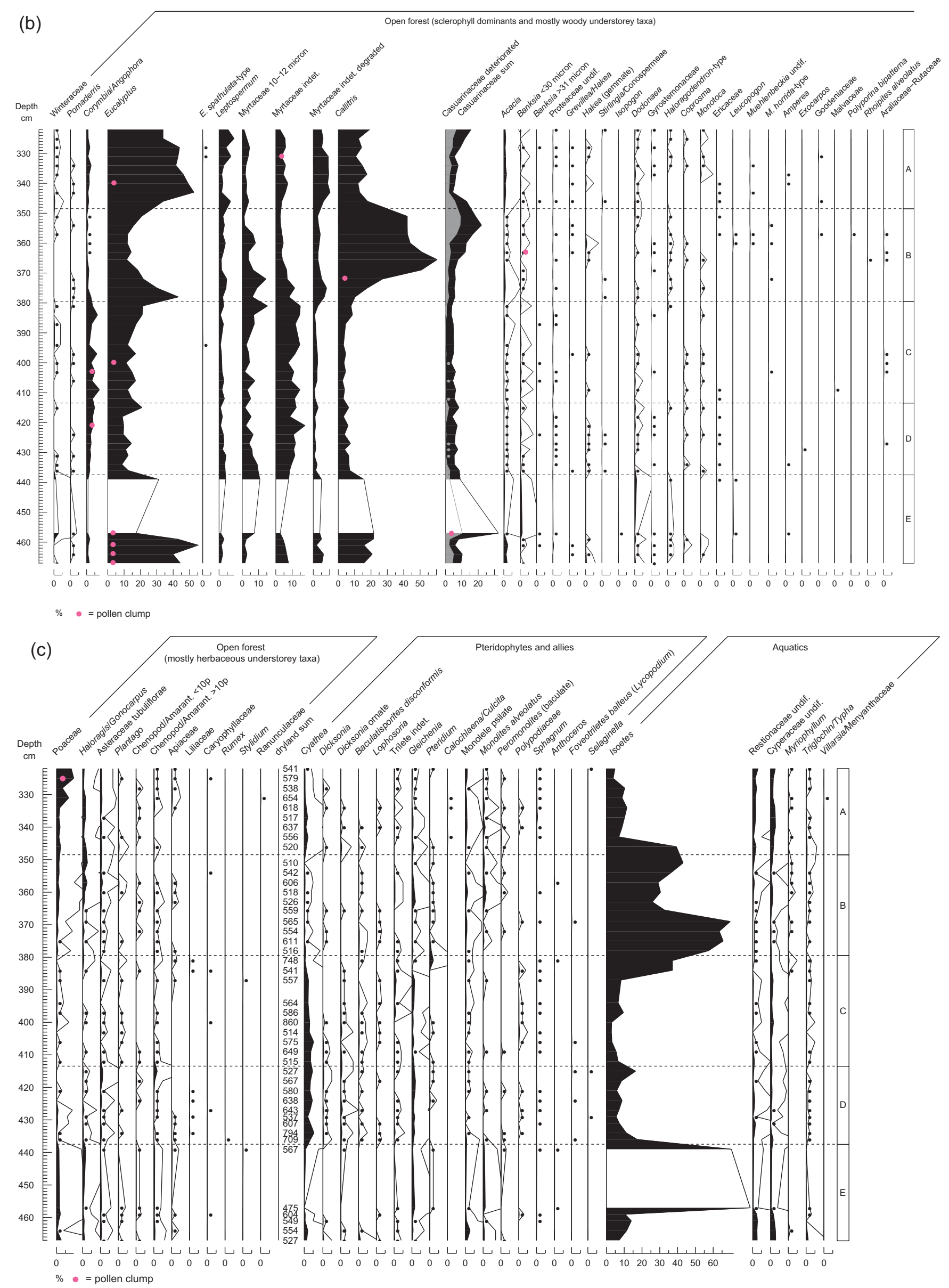

Figure 4. (Continued). 
1), with low moisture content and LOI (Fig. 3), is separated from black (Munsell N2/0, LOI 20-30\%), organic-rich clay by sharp boundaries above and below. The two pollen samples within the grey silty clay have high values for Casuarinaceae, Winteraceae, Isoëtes and deteriorated grains, and very low values for rainforest taxa and most ferns. High-resolution moisture and LOI sampling (Fig. 3) suggest that the grey silty clay is of homogeneous composition. Interpretation of this silty clay relies on insights from back-hoe excavation at SCB in 2002 , carried out within $\sim 20 \mathrm{~m}$ of the 2000 core site. This excavation revealed, at $\sim 5 \mathrm{~m}$ depth, a layer of grey, silty clay sediment blocks within the predominantly black, organic-rich clays. These blocks showed conspicuous bedding incongruent with the encompassing black sediment, and forming sharp boundaries with the latter (see Supporting information, Fig. S1). Based on their apparently rapid sedimentation (bedded rather than laminated), low organic content and high Isoëtes pollen counts (not shown), these sediments are interpreted as 'rip-up clasts': coherent sediment blocks transported from the lake margin, perhaps as a consequence of slope failure. In zone $E$, the sharp boundaries of the grey sediment at $438-458 \mathrm{~cm}$, and its low LOI and high Isoëtes values (Figs 3 and 4c), suggest that this interval is stratigraphically equivalent to rip-up clasts observed in the 2002 excavation. The insertion of a rip-up clast implies some disruption to the record, but since the vegetation sequence detailed here is part of an apparently complete, precession-scale vegetation cycle (Fig. 2), the duration of this disruption is likely to be small relative to the length of these cycles. It is probable, however, that the transition between the Eucalyptus-dominated vegetation of zone $\mathrm{E}$ and the rainforestrich vegetation of zone $\mathrm{D}$ is missing.

\section{Zone D, 413.5-437.5 cm (6516-8704 a within the age model)}

Podocarpaceae values are low, but rainforest angiosperms, dominated by Ilex and tricolpate Cunoniaceae, are high from the basal sample. The local presence of the latter is emphasized by pollen clumps. In Sniderman (2011), pollen preparation included sieving using a fine $(7 \mu \mathrm{m})$ mesh; here this step was omitted and hence the representation of small grains, such as Cunoniaceae and small-grained Eucalyptus types, is higher. In addition, several small pollen types (Ficus, Moraceae/Urticaceae, cf. Stemonuraceae, Concolpites cf. leptos) are consistently present that were absent or rare in the fine-sieved record. Initial high values of Ilex, Cunoniaceae and Elaeocarpus are joined sequentially by increased values for the rainforest taxa Rapanea, Moraceae/Urticaceae, Syzygium, Syzygium smithiitype, Quintinia, and Ficus, all of which persist with little change into zone C. Corymbia/Angophora increases steadily from the base of the zone; a pollen clump at $421 \mathrm{~cm}$ attests to the local presence of source trees. Many open-forest understorey taxa are consistently present at low values. Fern spores are consistently represented. Moisture and LOI rise within the first three samples and remain high throughout the zone (Fig. 3).

\section{Zone C, 379.5-413.5 cm (3284-6516 a within the age model)}

Cunoniaceae and Ilex values decrease upward, while most Podocarpaceae peak in the upper half of the zone before declining to low levels at the top of the zone. Other rainforest angiosperms maintain or increase their zone $D$ values (Rapanea, Quintinia, Ficus), and a few are best represented late in the zone (Symplocos, Rhodamnia/Rhodomyrtus, and Concolpites cf. leptos). Values for Eucalyptus are higher than in zone D, while Corymbia/Angophora values are at their highest in the diagram. Pollen clumps indicate local presence of Podocarpaceae and rainforest angiosperms and of Eucalyptus and Corymbia/Angophora. Values for Callitris and Casuarina- ceae remain low, and most open-forest taxa are inconsistently represented. Ferns, most notably Cyathea, decline upward, with Dicksonia disappearing altogether above $400 \mathrm{~cm}$. Moisture and LOI peak early in the zone, then slowly decline.

Zone B, 348.5-379.5 cm (1607-3284 a within the age model)

Callitris strongly dominates the zone ( $>50 \%$ of the pollen sum), while Eucalyptus and Casuarinaceae achieve substantial peaks early and late in the zone, respectively. Many rainforest taxa persist at trace levels within the lower half of the zone, especially Dacrycarpus, which is registered as consistently as in zone C. Values of wind-pollinated Nothofagus subgenus Brassospora here and in zone A probably represent a longdistance pollen component. The mesic, open-forest genus Pomaderris is consistently recorded early in the zone, while Corymbia/Angophora, like rainforest angiosperms, declines upward. Open-forest understorey taxa are more diverse than in zone C. Most fern spores are consistently present at low levels. Isoëtes continues a steep rise initiated in the upper part of zone C. Organic content declines to low levels towards the upper half of the zone.

\section{Zone A, 322-348.5 cm (0-1607 a within the age model)}

Eucalyptus dominates along with a range of open-forest understorey taxa, while Callitris and Casuarinaceae values are low. Many rainforest taxa, along with Winteraceae and Corymbia/Angophora, are represented more consistently than in zone B. For the first time within the diagram, Poaceae rises above $5 \%$ near the upper boundary of the zone, a pollen clump supporting the presence of local source plants. Cyathea has higher values than in zone B, but ferns are generally at consistent trace levels. Isoëtes values plummet above the basal sample, and Restionaceae and Cyperaceae are higher than in zones B, C or D. Moisture and LOI plateau or decline slightly upward.

\section{PCA summary of palynological variability}

The PCA ordination biplot (Fig. 5a) shows the disposition of pollen spectra within ordination space, and the evolution of community composition through time. The ordination of pollen types is dominated by the major sclerophyll taxa and Cunoniaceae (3c), reflecting the importance of these taxa in defining particular pollen zones. Axis 1 primarily separates rainforest taxa, with positive loadings, from sclerophyll taxa, with mostly negative loadings. Axis 2 explains less variance, but distinguishes Eucalyptus-dominated spectra of zones $\mathrm{A}$ and E from Callitris-dominated spectra of zone B, and, less clearly, Podocarpaceae-dominated spectra of zone $C$ from rainforest angiosperm-dominated spectra of zone $\mathrm{D}$. The ordination also reveals ecologically surprising behaviour in two taxa: (i) the eucalypts (sensu Ladiges et al., 2003) Corymbia/Angophora are generally open-forest canopy species which may occur near, but usually not within, closed-rainforest communities; their eigenvector coincides closely with that of Dacrydium and a range of rainforest angiosperms, implying that local populations responded positively to the same environmental forcings as rainforest taxa; (ii) Winteraceae are mesic understorey shrubs or trees of both wet Eucalyptus-dominated forests and rainforests. Their eigenvector coincides closely with that of Eucalyptus and Acacia, and shows no affinity with rainforest taxa. In order to elucidate differences between rainforest taxa free from the influence of the sclerophyll taxa, a second ordination (Fig. 5b) is presented of rainforest taxa only, based on pollen spectra for which it was possible to construct a rainforest pollen sum of $>100$ grains (samples between 381 and 

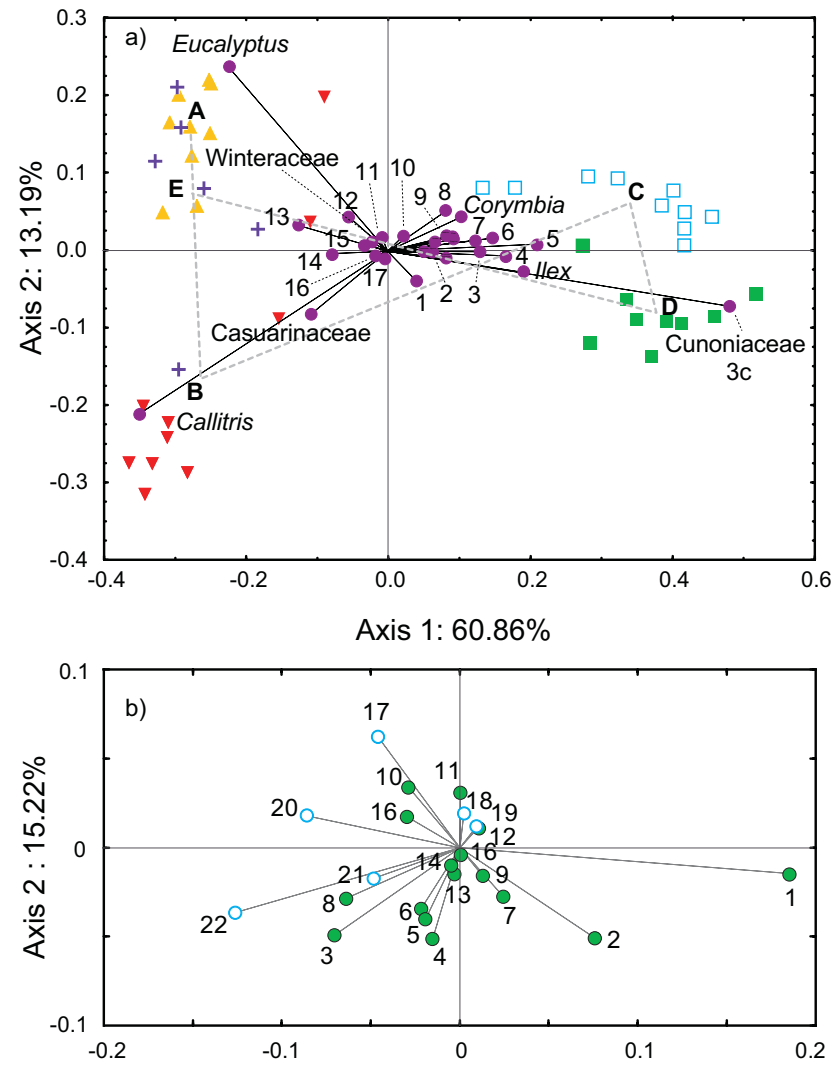

Axis $1: 56.71 \%$

Figure 5. PCA. (a) Biplot of SCB pollen spectra and major pollen types, samples coded to indicate zones dominated by Eucalyptus (upward-pointing triangles, zone A; crosses, zone E); rainforest angiosperms (filled squares, zone D); Podocarpaceae (open squares, zone C); and Callitris (downward-pointing triangles, zone B). Ordination of pollen taxa indicated by filled circles. Numbered taxa: 1 . Myrtaceae $<12 \mu \mathrm{m}$; 2. Moraceae/Urticaceae, Myrsine, and Cunoniaceae (2c); 3. Elaeocarpus; 4. Podocarpus; 5. Podosporites cf. microsaccatus; 6. Rapanea; 7. Phyllocladus; 8. Dacrydium; 9. Quintinia, Ficus, Syzygium, and Acmena; 10. Rhodamnia/Rhodomyrtus; 11. Dodonaea; 12. Acacia; 13. Poaceae; 14. Gonocarpus/Haloragus; 15. Leptospermum; 16. Asteraceae; 17. Banksia $(<30 \mu \mathrm{m})$. (b) Separate ordination of rainforest taxa only. Angiosperms (green circles): 1. Cunoniaceae (3c); 2. Ilex; 3. Ficus. 4. Quintinia; 5. Acmena; 6. Rapanea; 7. Moraceae/Urticaceae; 8. Syzygium; 9. cf. Stemonuraceae; 10. Symplocos; 11. Cunoniaceae (2c); 12. Elaeocarpus; 13. Araliaceae; 14. Myrsine; 15. Lomatia; 16. Concolpites cf. leptos; Podocarpaceae (blue circles):17. Podocarpus; 18. Dacrycarpus; 19. Podocarpidites sp. 20. Dacrydium; 21. Phyllocladus; 22. Podosporites cf. microsaccatus. This figure is available in colour online at wileyonlinelibrary.com.

$436 \mathrm{~cm}$, inclusive). Axis 1 (Fig. 5b) largely separates taxa prominent in zone $\mathrm{C}$ (negative loadings, including the major Podocarpaceae) from those prominent in zone D (positive loadings). Two Podocarpaceae (Dacrycarpus and Podocarpidites sp.) vary primarily with angiosperm taxa, confirming that the zone D-C transition was more complex than simply a change from angiosperm to conifer dominance. Instead, the ordination emphasizes the variable floristic composition of rainforest during zones $\mathrm{D}$ and $\mathrm{C}$.

\section{Age model}

The 438-458 cm interval was excluded from the age model and from subsequent charcoal analyses, based on its interpretation as a rip-up clast. This exclusion is represented in Fig. 6 by a vertical beige line at the zone D-E boundary. The age model is zeroed at the uppermost sample $(322 \mathrm{~cm})$, and extends for 9694 a below this. Although the position and magnitude of deviations from the calculated mean sediment deposition time of $75.9 \mathrm{a} \mathrm{cm}^{-1}$ may be incorrectly estimated, modelled deposition times of $>100 \mathrm{a} \mathrm{cm}^{-1}$ are based on 316 individual measured varves from three sediment samples with mean thicknesses $<100 \mu \mathrm{m}$ in several parts of the $40 \mathrm{~m} \mathrm{SCB}$ core (mean of all 316 samples $=92.9 \mu \mathrm{m}, \sigma=35.53$ ). However, a more general source of error is the assumption that slowly varying LOI and sediment moisture content are perfect surrogates for sediment accumulation rate. Conceivably, real sediment deposition times may have been more bimodal, with two stable states (cf. Peckham et al., 2006), one close to observed times of $115 \mathrm{a} \mathrm{cm}^{-1}$, perhaps during most of high-LOI and high-moisture zones $\mathrm{D}$ and $\mathrm{C}$; and a second with short times, perhaps shorter than those modelled during low-LOI and low-moisture zone $\mathrm{B}$. If so, zones $\mathrm{D}$ and $\mathrm{C}$ might represent ca. 6325 a $\left(55 \mathrm{~cm} \times 115 \mathrm{a} \mathrm{cm}^{-1}\right)$ rather than the ca. $5420 \mathrm{a}$ estimated by the age model, a difference of $\sim 15 \%$. Thus the estimate of the duration of zones D and C, and of the time between fires in these zones, may be underestimated by $\sim 15 \%$, while the duration of zone $B$, and of time between fires in this zone, may be overestimated by a similar amount.

\section{Fire history}

Although macrocharcoal studies typically have focused on discerning the timing of individual fire events within small catchments (Whitlock and Millspaugh, 1996), changes in the background component of a macrocharcoal record also convey important information (Marlon et al., 2006). Background charcoal integrates slowly varying changes in charcoal production and transport that are likely to primarily reflect changes in biomass burning (Higuera et al., 2010). Correlations between pollen types and background charcoal accumulation rate should therefore reveal relationships between vegetation type and biomass burning. Of the major pollen groups (Fig. 6), Eucalyptus was strongly positively correlated, and Podocarpaceae strongly negatively correlated, with background charcoal accumulation rate (Eucalyptus $r=0.567, P<0.000$; Podocarpaceae $r=-0.446, P=0.003 ; n=42$ ), while correlations between background charcoal and rainforest angiosperms, Callitris, and Casuarinaceae were all non-significant. This implies that the greatest biomass combustion coincided with periods of Eucalyptus-dominated vegetation during zones A and $\mathrm{E}$, and that the least biomass combustion coincided with the period of Podocarpaceae-rich vegetation during the latter half of zone $\mathrm{C}$.

By comparison, the occurrence of charcoal peaks (Fig. 6) shows only modest variability between zones. Thirteen charcoal peaks (and one in zone $\mathrm{C}$ that fails to pass the minimum count test) are detected, at least two in each zone. Some charcoal peaks are closely associated with times of change in palynological dominance (e.g. changes in rainforest dominance at 6900 and $5025 \mathrm{a}$ in the age model), but others are not associated with any such change (e.g. at 5625, 7575 and $7725 \mathrm{a}$ in the age model), even in rainforest vegetation that might be considered as highly fire sensitive. The distribution of identified charcoal peaks suggests that local fires occurred at least once every 200-800 years, in both sclerophyll and rainforest angiosperm-dominated vegetation phases. An extended period when no charcoal peak is detected, in the early part of rainforest angiosperm-dominated zone D, appears to be largely an artefact of the use of a smoothing window that incorporated the very high peaks in zone $\mathrm{E}$. This was confirmed by experimental removal of zone $\mathrm{E}$ from the record (not shown), which allowed two charcoal peaks to be identified at ca. $8400 \mathrm{a}$ 
Figure 6. Charcoal peak analysis using CharAnalysis (Higuera et al., 2009), and summary of major pollen groups, plotted on depth and age model axes for comparison. (a) SCB $322-$ $467 \mathrm{~cm}$ summary pollen diagram, plotted on the age model developed in this paper. (b) Charcoal peak series $\left(\mathrm{C}_{\text {interpolated }}\right)$ interpolated to 75-year intervals, and background charcoal $\left(C_{\text {background }}\right)$ defined by 1500 -year trends. (c) Charcoal peaks ( $\left.C_{\text {interpolated }}-C_{\text {background }}\right)$, thresholds defining charcoal noise (lines), and peaks (crosses) identified (dot failed to pass minimum-count test). This figure is available in colour online at wileyonlinelibrary.com.

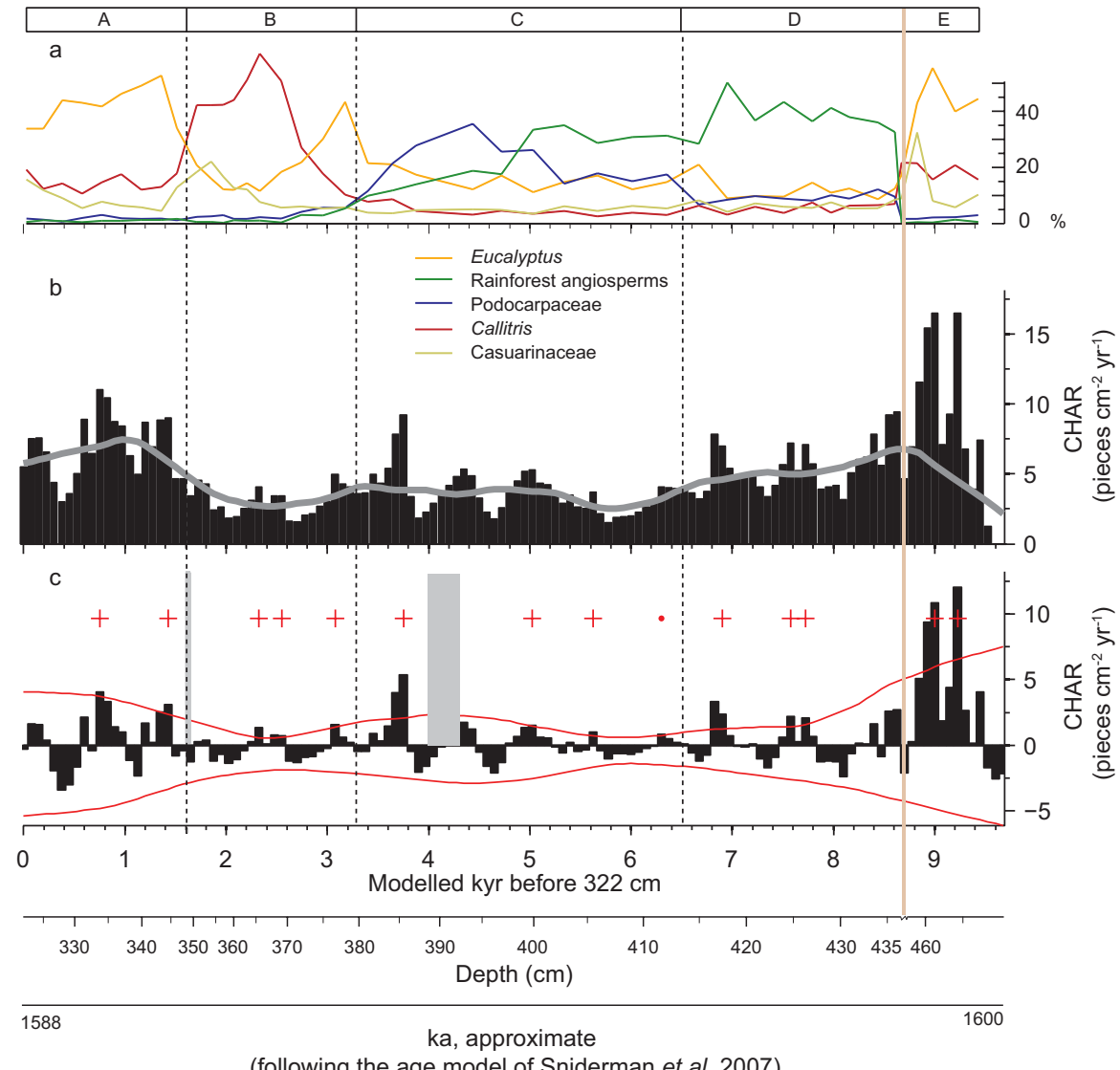

(following the age model of Sniderman et al. 2007)

+ Charcoal peaks identified as local fire events

- Charcoal peaks which fail to pass a minimum count test

and $8600 \mathrm{a}$ in the age model. The longest interval between detected charcoal peaks is in the upper half of zone C, straddling the interval of Podocarpaceae-dominated vegetation, when no charcoal peak is detected for ca. 1250 years.

\section{Discussion}

\section{Early Pleistocene forest succession}

The $322-470 \mathrm{~cm}$ record illustrates in detail approximately half of one precession-paced, Early Pleistocene vegetation cycle in upland southeastern Australia. The pollen zones demarcate five intervals of distinct forest composition, charting the development and subsequent collapse of rainforest populations, and their apparently rapid replacement by sclerophyll communities. Keeping in mind its uncertainties, the age model provides a first-order basis for estimating the duration of these vegetation phases, the rapidity of transitions between them, and the frequency of local fire events within them.

Zone E corresponds to the final ca. 1000 years of a phase when local vegetation was dominated by Eucalyptus, though the presence of both rainforest and open-forest understorey taxa at trace levels implies that the landscape included a mosaic of rainforest and sclerophyll forest. Three lines of evidence indicate that the biological productivity of the Eucalyptusdominated forests was high, probably with relatively dense, woody understoreys. First, the low values for Poaceae and Asteraceae are recorded in the Holocene of southern Australia only in regions with tall, relatively dense forests (McKenzie and Kershaw, 2004); second, palaeoclimatic reconstructions indicate Eucalyptus-dominated phases were warmer and wetter than modern climate at SCB (Sniderman et al., 2009); third, the positive correlation between Eucalyptus and background charcoal implies that large amounts of sclerophyll-related biomass were combusted in wildfires. Hence these forests may have been broadly analogous to modern, biologically productive, wet sclerophyll or tall open forests (Ashton and Attiwill, 1994), which experience rare, but severe fires.

During zone D, angiosperm-dominated rainforests expanded and progressively diversified locally, although open-canopied, sclerophyll forests with diverse understoreys must have remained present. The successive expansion of 10 rainforest angiosperm taxa, starting with Ilex and Cunoniaceae (3c) in the basal sample, and extending to Ficus around $409 \mathrm{~cm}$, represent taxon-specific responses to the onset of a mesic phase within an Early Pleistocene insolation cycle. The age model indicates that this period of rainforest expansion lasted for ca. 2600 years, while the lags separating the expansion of successive rainforest taxa were ca. $250-500$ years (corresponding to $4-5 \mathrm{~cm}$ ). These lags are unlikely to reflect the variable vagility of species expanding from geographically discrete refugia, because most rainforest taxa are present in trace quantities from the basal most sample of zone D; they are thus more likely to reflect differences in intrinsic rate of population growth. Lags of similar magnitude were recorded during early Holocene rainforest expansion in northeast Queensland (Chen, 1988).

By contrast, the declining values of most rainforest angiosperms and the increased importance of Podocarpaceae in zone $\mathrm{C}$ are likely to reflect a substantial regional climatic change. Unfortunately, palaeoclimate reconstructions for SCB 
(Sniderman et al., 2009) did not have sufficient stratigraphic or climatic resolution to distinguish the climates of angiospermand conifer-dominated rainforest phases, and indicate that rainfall was uniformly high during both sclerophyll- and rainforest-dominated phases. However, the significant negative correlation between background charcoal and Podocarpaceae, and the $>1000$-year-long interval between charcoal peaks in the upper half of zone $C$, suggest that maintenance of Podocarpaceae forests depended on long fire-free periods, which presumably required a climate that was very wet and/or very stable. By comparison, the charcoal peaks detected in zone D imply that the regional climate, while clearly wet enough to support complex, species-rich rainforest, experienced episodes favourable to ignition, at least on centennial timescales. This dominance by Podocarpaceae of the wettest, and/or most stable portion of a climate cycle contrasts with the situation on the Atherton Tableland in northeast Queensland, where Late Quaternary rainforest phases dominated by conifers, including Podocarpus, are interpreted as drier than those dominated by angiosperms (Kershaw, 1976). This difference may simply reflect the progressive loss of the most mesic podocarps from mainland Australia during the Pleistocene. Closer bioclimatic and ecological analogues may be found in New Zealand, where transitions from conifer to angiosperm dominance are associated with early-late interglacial transitions (Kershaw and McGlone, 1995).

The abrupt transition from Podocarpus- to Callitris-dominated spectra across the S-4/S-3 boundary in the pollen record of Sniderman (2011) is shown here to be a more gradual transition in which, over some 800 years (from 384 to $372 \mathrm{~cm}$ ), rainforests largely collapsed, though many component taxa remained locally present; and Callitris-dominated forest expanded dramatically. According to the age model, the subsequent episode of very high Callitris values (from $\sim 372$ to $346 \mathrm{~cm}$ ) lasted for some 1200 years, after which Callitris declined rapidly as the vegetation returned to a phase of Eucalyptus dominance seen previously in the lowermost few samples of zone D. The transition from high Callitris values, at $351 \mathrm{~cm}$, to high Eucalyptus values, at $343 \mathrm{~cm}$, was evidently accomplished in only ca. 400 years.

\section{Fire history and dynamics}

Several factors suggest that fire return times estimated here underestimate fire activity within the SCB catchment: (a) the presence of two core gaps, each spanning a few $\mathrm{cm}$; (b) the stratigraphic assumptions involved in excluding the 'rip-up clast' from the age model; (c) the heterogeneity of background charcoal values between pollen zones, which means that the local window used to model charcoal noise distributions in some cases has suppressed relatively small peaks. For example, charcoal peaks near the base of zone $\mathrm{D}$ failed to pass peak detection tests only because of very high charcoal values in underlying zone E; and (d) the sampling resolution (ca. 76 a), which is coarse relative to typical timescales of modern forest wildfires. Because of this sampling resolution, fires at intervals much less than one or two centuries probably cannot be detected. Sampling theory (Clark, 1988; Higuera et al., 2007) indicates that sample resolution must be $<0.12-0.2 \times$ the mean fire return time to detect individual fires, which suggests that the minimum detectable fire return time here is $375-625$ years. In addition, the locally calculated signal-to-noise index (SNI) fluctuates around 3, which indicates that charcoal peaks identified as local fires are on average three standard deviations higher than the mean of the modelled noise distribution of peak charcoal series. Kelly et al. (2010) advise that peaks cannot be reliably distinguished from noise where $\mathrm{SNI}<3$, so the peaks identified here should be accepted cautiously. The most likely source of a low $\mathrm{SNI}$ is the coarse sample resolution, which may have allowed multiple fire events to be conflated within single samples.

Despite these caveats, it is difficult to avoid the conclusion that fire was a recurrent feature of the local environment around $\mathrm{SCB}$. The simplest interpretation of the peak charcoal record is that, during phases dominated by Eucalyptus, Callitris, and rainforest angiosperms, fires occurred within the SCB catchment at least every few centuries. Given the strong dependence of most Eucalyptus species on fire for regeneration (Ashton and Attiwill, 1994), this is likely to be a minimum estimate of fire frequency for intervals dominated by that genus. Conversely, it is likely that the longest interval without a charcoal peak (ca. 1250 years, during the Podocarpaceae-dominated phase) reflects the real rarity of fire within the conifer-dominated rainforest vegetation.

The peak component of the charcoal accumulation record provides a basis for detecting high-frequency fire events, while the background component provides a basis for placing these events in the context of lower-frequency changes in biomass production, fuel load, and combustion. Thus the positive correlation between background charcoal and Eucalyptus, and the evidence for regular fires every few centuries within Eucalyptus-dominated phases, is consistent with the known fire dependence of modern Eucalyptus-dominated communities (Gill, 1997; Bowman, 2000). By comparison, the background charcoal record implies that Casuarinaceae- and Callitrisdominated vegetation at SCB was less biologically productive than Eucalyptus-dominated vegetation, yet the presence of two charcoal peaks during the Callitris-dominated part of zone B suggests that this community burnt as frequently as Eucalyptusdominated forests. In contrast, neither of the two brief peaks of Casuarinaceae pollen (Fig. 6) are associated with a charcoal peak, which suggests that Casuarinaceae at SCB were not very flammable, or occurred when environmental conditions were not conducive to fire.

The significant negative correlation of Podocarpaceae with background charcoal, and the absence of charcoal peaks when Podocarpaceae representation was highest, imply that fire was very infrequent in these podocarp-dominated forests. This is consistent with Holocene charcoal histories from relatively dry parts of New Zealand, where Podocarpaceae were common forest dominants. There, prior to the arrival of humans, fires burnt individual locations with a return time of ca. 1500-2000 years (Ogden et al., 1998), probably long enough for complete forest recovery even in the absence of any specific biological adaptations to fire. By comparison, fires appear to have burnt at least once every ca. 500-600 years during the angiospermdominated phase of rainforest expansion in zones D and C, perhaps no less frequently than during Eucalyptus or Callitrisdominated vegetation phases. This is similar to fire return times of ca. 250-1000 years which occurred in northeastern Queensland upland rainforest during the early and late Holocene, with no obvious change in forest composition (Haberle, 2005).

Given the combination of rainforest and sclerophyll taxa in SCB pollen spectra, it is uncertain whether fire penetrated rainforests, or whether it was confined to relatively flammable sclerophyll communities, and perhaps served to maintain a local mosaic of relatively fire-tolerant and fire-sensitive communities. The Eucalyptus pollen clump at $400 \mathrm{~cm}$, in rainforest-dominated zone $\mathrm{C}$, implies that Eucalyptus was locally present even when its pollen percentages were $<15 \%$. However, in zone D the very low values for Eucalyptus make it difficult to imagine that the local fires inferred for that zone were confined to a sclerophyll component of a vegetation 
mosaic, and more likely that they burnt within rainforest stands. In any case, fire return times measured in centuries appear to have been compatible with rainforest persistence, and were a regular feature of these sclerophyll-rainforest mosaics. Given that rainforest diversity does not decline over the $280 \mathrm{ka}$ of the SCB record (Fig. 2), these fires clearly did not encourage a shift towards sclerophyll-dominated vegetation (cf. Jackson, 1968).

The evidence presented here has implications for understanding late Neogene and Quaternary records of Australian fire history. Martin (1987) documented relatively high charcoal concentrations in middle-late Miocene Murray Basin pollen records dominated by Eucalyptus, but which also included a substantial rainforest component. She interpreted these assemblages as analogous to modern wet sclerophyll forest in which fire-dependent canopy species and fire-intolerant rainforest understorey taxa coexist in an ecotonal or seral relationship. Kershaw et al. (1994) questioned whether extensive, ecotonal wet sclerophyll forests could have been maintained over millions of years without progressively eliminating rainforest. They suggested that such forests may have been less flammable than modern analogues. However, the SCB charcoal record indicates that multi-century fire return times were a feature of the dynamics of southern Australian rainforest in the Early Pleistocene. This suggests that the distinction between a putatively non-flammable, resource-controlled 'green world' and a fire-controlled 'black world' (Bond, 2005) was not so stark during the late Neogene, and that fire-'sensitive' communities have been more or less regularly burnt - if rarely, by modern standards - for millions of years. If so, it is likely that the retreat of Australian rainforest in the late Neogene or Quaternary was not a response to fire per se. Instead, it is likely that an increase in fire frequency, possibly encouraged by novel rainfall seasonality some time after ca. 1.5 Ma (Sniderman et al., 2009), encouraged diversification and spread of firepromoting floras while exceeding thresholds of fire tolerance for many rainforest species. The Early Pleistocene evidence reviewed here confirms Kershaw et al.'s (2002) inference from late Quaternary data that it is climate primarily that controls vegetation, while fire plays a secondary role.

\section{Supporting information}

Additional supporting information can be found in the online version of this article:

Fig. S1. Image of grey 'rip-up clast' exposed in horizontal cut bench, at $\sim 4.5 \mathrm{~m}$ depth in 2002 excavation.

Please note: This supporting information is supplied by the authors, and may be re-organized for online delivery, but is not copy-edited or typeset by Wiley-Blackwell. Technical support issues arising from supporting information (other than missing files) should be addressed to the authors.

Acknowledgements. This paper is based on work done while J.M.K.S. was the recipient of an Australian postgraduate award at Monash University. We thank two anonymous reviewers for their comments, which substantially improved this paper.

Abbreviations. LOI, loss on ignition; PCA, principal component analysis; SCB, Stony Creek Basin; SNI, signal-to-noise index.

\section{References}

Ashton DH, Attiwill PM. 1994. Tall open-forests. In Australian Vegetation (2nd edn), Groves RH (ed). Cambridge University Press: Cambridge, UK; 157-196.

Bennett KD. 2005. Documentation for Psimpoll 4.25 and Pscomb 1.03: $C$ programs for plotting pollen diagrams and analysing pollen data. Department of Earth Sciences, University of Uppsala, Uppsala.
Available: http://www.chrono.qub.ac.uk/psimpoll/psimpoll.html [27 September 2011].

Bennett KD, Boreham S, Sharp MJ, et al. 1992. Holocene history of environment, vegetation and human settlement on Catta Ness, Lunnasting, Shetland. Journal of Ecology 80: 241-273.

Bond WJ. 2005. Large parts of the world are brown or black: a different view on the 'Green World' hypothesis. Journal of Vegetation Science 16: $261-266$.

Bowman DMJS. 2000. Australian Rainforests: Islands of Green in a Land of Fire. Cambridge University Press: Cambridge, UK.

Chen Y. 1988. Early Holocene population expansion of some rainforest trees at Lake Barrine basin, Queensland. Australian Journal of Ecology 13: 225-233.

Clark JS. 1988. Particle motion and the theory of charcoal analysis: source area, transport, deposition, and sampling. Quaternary Research 30: 67-80.

Clark JS, Royall PD. 1995. Particle-size evidence for source areas of charcoal accumulation in late Holocene sediments of eastern North American lakes. Quaternary Research 43: 80-89.

Conedera M, Tinner W, Neff C, et al. 2009. Reconstructing past fire regimes: methods, applications, and relevance to fire management and conservation. Quaternary Science Reviews 28: 555-576.

Dean WE. 1974. Determination of carbonate and organic matter in calcareous sediments and sedimentary rocks by loss on ignition: comparison with other methods. Journal of Sedimentary Petrology 44: 242-248.

Gavin DG, Hu FS, Lertzman K, et al. 2006. Weak climatic control of stand-scale fire history during the late Holocene. Ecology 87: 17221732.

Gill AM. 1997. Eucalypts and fires: interdependent or independent? In Eucalypt Ecology: Individuals to Ecosystems, Williams J, Woinarski J (eds). Cambridge University Press: Cambridge, UK; 151-167.

Haberle SG. 2005. A 23,000-yr pollen record from Lake Euramoo, wet tropics of NE Queensland, Australia. Quaternary Research 64: 343356.

Higuera PE, Peters ME, Brubaker LB, et al. 2007. Understanding the origin and analysis of sediment-charcoal records with a simulation model. Quaternary Science Reviews 26: 1790-1809.

Higuera PE, Brubaker LB, Anderson PM, et al. 2009. Vegetation mediated the impacts of postglacial climate change on fire regimes in the south-central Brooks Range, Alaska. Ecological Monographs 79: 201-219.

Higuera PE, Gavin DG, Bartlein PJ, et al. 2010. Peak detection in sediment-charcoal records: impacts of alternative data analysis methods on fire-history interpretations. International Journal of Wildland Fire 19: 996-1014.

Jackson WD. 1968. Fire, air, water and earth: an elemental ecology of Tasmania. Proceedings of the Ecological Society of Australia 3: 9-16.

Jordan GJ, Bromfield KE, Sniderman JMK, et al. 2007. Diverse fossil epacrids (Styphelioideae; Ericaceae) from Early Pleistocene sediments at Stony Creek Basin, Victoria, Australia. International Journal of Plant Sciences 168: 1359-1376.

Joyce EB. 1992. The west Victorian uplands of southeastern Australia: origin and history. Earth Surface Processes and Landforms 17: 407418 .

Kelly RF, Higuera PE, Barrett C, et al. 2010. A signal-to-noise index to quantify the potential for peak detection in sediment-charcoal records. Quaternary Research 75: 11-17.

Kershaw AP. 1976. The Late Pleistocene and Holocene pollen diagram from Lynch's Crater, north-eastern Queensland, Australia. New Phytologist 77: 469-498.

Kershaw AP, McGlone MS. 1995. The Quaternary history of the southern conifers. In Ecology of the Southern Conifers, Enright NJ, Hill RS (eds). Melbourne University Press: Melbourne; 30-63. Kershaw AP, Martin HA, McEwan Mason JRC. 1994. The Neogene: a period of transition. In History of the Australian Vegetation: Cretaceous to Recent, Hill RS (ed.). Cambridge University Press: Cambridge, UK; 299-327.

Kershaw AP, Clark JS, Gill M, et al. 2002. A history of fire in Australia. In Flammable Australia: The Fire Regimes and Biodiversity of a Continent, Bradstock R, Williams J, Gill M (eds). Cambridge University Press: Cambridge, UK; 3-25. 
Ladiges PY, Udovicic F, Nelson G. 2003. Australian biogeographical connections and the phylogeny of large genera in the plant family Myrtaceae. Journal of Biogeography 30: 989-998.

Lourens LJ, Antonarakou A, Hilgen FJ, et al. 1996. Evaluation of the Plio-Pleistocene astronomical timescale. Paleoceanography 11: 391-413.

Marlon J, Bartlein PJ, Whitlock C. 2006. Fire-fuel-climate linkages in the northwestern USA during the Holocene. Holocene 16: 1059_ 1071.

Martin HA. 1987. Cainozoic history of the vegetation and climate of the Lachlan River region, New South Wales. Proceedings of the Linnean Society of New South Wales 109: 213-257.

McKenzie GM, Kershaw AP. 2004. A Holocene pollen record from cool temperate rainforest, Aire crossing, the Otway region of Victoria, Australia. Review of Palaeobotany and Palynology 132: 281-290.

Millspaugh SH, Whitlock C. 1995. A 750-year fire history based on lake sediment records in central Yellowstone National Park, USA. The Holocene 5: 283-292.
Ogden J, Basher L, McGlone M. 1998. Fire, forest regeneration and links with early human habitation: evidence from New Zealand. Annals of Botany 81: 687-696.

Peckham SD, Chipman JW, Lillesand TM, et al. 2006. Alternate stable states and the shape of the lake trophic distribution. Hydrobiologia 571: 401-407.

Sniderman JMK. 2011. Early Pleistocene vegetation change in upland south-eastern Australia. Journal of Biogeography 38: 1456-1470.

Sniderman JMK, Pillans B, O'Sullivan PB, et al. 2007. Climate and vegetation in southeastern Australia respond to southern hemisphere insolation forcing in the late Pliocene-early Pleistocene. Geology 35 : $41-44$.

Sniderman JMK, Porch N, Kershaw AP. 2009. Quantitative reconstruction of Early Pleistocene climate in southeastern Australia and implications for atmospheric circulation. Quaternary Science Reviews 28: 3185-3196.

Whitlock C, Millspaugh SH. 1996. Testing the assumptions of fire history studies: an examination of modern charcoal accumulation in Yellowstone National Park, USA. The Holocene 6: 7-15. 